\title{
Beyond Survey Measures: Exploring International Male Graduate Students' Sense of Belonging in Electrical Engineering
}

\author{
Anthony Lising Antonio ${ }^{1}$ and Chanwoong Baek ${ }^{2}$ \\ ${ }^{1}$ Stanford University Graduate School of Education, Stanford, California, USA \\ ${ }^{2}$ Department of Education, University of Oslo, Oslo, Norway
}

\section{Acknowledgements}

The authors have contributed equally and are listed in alphabetical order.

Correspondence concerning this article should be addressed to Chanwoong Baek, Department of Education, Faculty of Educational Sciences, University of Oslo, 0317 OSLO, Norway. Email: chanwoong.baek@iped.uio.no 


\begin{abstract}
Purpose

Although a student's sense of belonging is a key factor of persistence in higher education, research on international students' belonging tends to rely on domain-agnostic survey measures and promote interpretations that focus mainly on social integration and adjustment. This study examines (1) how male international graduate students in engineering understand and describe their sense of belonging and (2) how they perceive its development at their institution.

\section{Design/methodology/approach}

We conducted in-depth interviews with twelve male electrical engineering doctoral students at a selective research university in the United States. This interpretive approach allowed students to articulate their subjective understanding of belonging within a specific disciplinary context.

\title{
Findings
}

Contrary to the broad notion that the social domain is the primary locus of students' sense of belonging, participants emphasized the academic domain when referring to their struggles with, and attempts to develop, a sense of belonging. Results suggest that the meritocratic culture of engineering education may influence students to prioritize the academic domain when conceptualizing and developing their belonging. Moreover, the strong academic motivation endemic to international students pursuing graduate education at a top American research university intensified this mechanism.

\section{Originality}

This study argues that universities seeking to enhance international graduate students' sense of belonging can be more intentional in providing opportunities for students to establish positive academic identities. Furthermore, addressing students' non-academic identity and 
marginalization as relevant and essential topics in engineering will expand their understanding of what means to belong.

Keywords: sense of belonging, international students, engineering education, student experience 


\section{Introduction}

In the era of globalization, the increased mobility of students across national borders has been one of the main interests for scholars in education. Internationalization of higher education has become a global phenomenon, and the United States has been one of the most active countries since World War II when it structured what used to be individual enrollments into diverse programs and projects (De Wit, 2002). As of the 2019-2020 academic year, the US is the largest host country for international students with more than one million enrollments. An important and growing population, international graduate students numbered almost 400,000 in US universities and colleges that year - approximately a 27 percent increase from ten years earlier (IIE, 2020). Among doctoral students, only 67 percent complete their graduate studies, however, and with American institutions actively recruiting them for both educational and economic reasons, the success of international graduate students is garnering attention (Andrade and Evans, 2009; Council of Graduate Schools, 2008). To attain the full benefits of international student contributions, higher education administrators have started to focus on international student adjustment and persistence as much as recruitment (Andrade and Evans, 2009).

International graduate student enrollments are particularly critical for the continued vitality of American engineering programs. International students make up large majorities in graduate engineering programs, particularly in electrical engineering where they compose about 80 percent of full-time enrollments (National Foundation for American Policy, 2017).

Consequently, enrollment losses among international students have disproportionate impact on these programs. Many international graduate students return to their home countries after graduation, which also contributes to a reduction in engineering talent in the US (Han et al., 2015; Mervis, 2017). While reasons for departure may vary for each student, scholars have 
consistently noted that international students' successful adjustment plays an important role in their decision to remain in the US (Barber and Morgan, 1987; Stuen et al., 2012).

Among the key predictors of adjustment and persistence is a student's sense of belonging. For domestic undergraduates, a strong sense of belonging has been found to correlate with institutional commitment and intentions to persist (Tinto, 2017), academic progress (Meeuwisse et al., 2010), academic performance (Walton and Brady, 2017), social and academic adjustment (Ostrove and Long, 2007), and overall satisfaction with college (Elliott, 2002). It is unclear, however, whether those relationships hold similarly for international students or whether even the construct itself is invariant across populations. International students may experience a sense of belonging differently because of their relative unfamiliarity with the cultural, social and linguistic environment of US colleges and universities (Curtin et al., 2013; Rivas et al., 2019). In such cases, one's sense of belonging may be interpreted in terms of cultural acceptance or identification, social belonging and integration into a community, or academic membership into a selective intellectual community (Curtin et al., 2013; Gu et al., 2010). In addition, research has been almost exclusively focused on undergraduates, whose different motivations, experiences, and backgrounds relative to graduate students further suggest that the concept and its relationship to persistence among international graduate students may differ from those predominant in the literature (Laufer and Gorup, 2019; Strayhorn, 2012).

In this study, we explore how international graduate students in electrical engineering understand and describe their sense of belonging and how they perceive its development during their graduate program. We focus on male students acknowledging both the lack of studies of male international graduate students and the distinctive, gendered experiences of engineering students that ultimately create more challenging environments for women (Faulkner, 2000; 
Franzway et al., 2009). Due to students' varying experiences across different fields of study (Kuh et al., 2006), we additionally consider how the specific context of electrical engineering education may contribute to conceptions of belonging.

\section{Literature Review}

Sense of Belonging as a Conceptual Construct

Research on sense of belonging grew out of an effort to improve retention studies by emphasizing the cognitive and affective aspects of Tinto's $(1975,1987)$ oft-cited antecedents to retention, social and academic integration. In particular, Hurtado and Carter (1997) argued that common behavioral indicators of social integration were often less valid for students of color, as they typically measured involvement in mainstream clubs and activities and ignored participation in ethnic-themed organizations and cultural forms of involvement like activism, the arts, and community service. They noted that adding a distinct psychological measure of social integration such as sense of belonging to retention models allows for identification of a broader range of activities that might contribute to a more inclusive understanding of social integration and, consequently, retention. Since that introduction, numerous studies have engaged the construct in research on college student retention, adjustment, and transition.

The construct of belonging in education has rarely been studied conceptually, however. Scholars have acknowledged that "sense of belonging as a theoretical construct has been little studied and inconsistently defined in the higher education literature" (Johnson et al., 2007, p. 527), yet there has been little effort to explore the construct's meaning in greater depth. Instead, studies most frequently focus on identifying various factors that are correlated to a sense of belonging among students. As a result, even when scholars identify such factors, it is difficult for 
practitioners and administrators to develop interventions or policies because the construct can be quite broad.

In educational contexts, for example, scholars have defined a sense of belonging as: (a) “an individuals' sense of identification or positioning in relation to a group or to the college community, which may yield an affective response" (Tovar and Simon, 2010, p. 200); and (b) “students' sense of being accepted, valued, included, and encouraged by others (teachers and peers) in the academic classroom setting and of feeling oneself to be an important part of the life and activity of the class" (Goodenow, 1993, p. 25). Both conceptions imply a notion of group membership but also a multi-dimensionality that at minimum includes social and academic domains. Studies of sense of belonging generally retain the notion of group membership but overlook this complexity of college communities.

Along with this the lack of conceptual exploration, the vast majority of the research on belonging in higher education uses survey methods that ask students to respond to Likert-scale items adapted from Bollen and Hoyle's (1990) Sense of Belonging Scale. Critically, this scale does not specify a domain in which respondents are to assess their sense of belonging. For example, agreement with the statement, "I feel a sense of belonging to this university," is common in these survey-based studies (e.g., Hurtado and Carter, 1997; Hurtado and Ponjuan, 2005; Johnson et al., 2007; Museus et al., 2017; O'Meara et al., 2017). As such scale items rely on respondent interpretation, it is possible that the basis for assessing one's sense of belonging may vary by respondent. The lack of domain specificity, which Hurtado and Carter (1997) critique in Tinto's concept and measurement of social integration, also applies to sense of belonging measures and may systematically yield biased measures for particular populations of students. A few scholars have examined academic belonging (Hoffman et al., 2002; Freeman et 
al., 2007; Walton and Cohen, 2007), raising the possibility that different domains of belonging have been captured by studies that provide no domain specificity in their measures.

\section{Determinants of Sense of Belonging}

Researchers have identified several key indicators of college students' sense of belonging in higher education: race/ethnicity, gender, valued group membership, and relationship with peers and faculty/staff. Racial minority students experience a weaker sense of belonging than White/Caucasian students, as do female students relative to than men, particularly in STEM fields (Johnson et al., 2007; Johnson, 2012). Involvement and affiliation with a campus organizations have a positive association with students' sense of belonging (Hurtado and Carter, 1997; Slaten et al., 2014). Furthermore, healthy interactions with peers and faculty/staff, as well as their support are positively related with students' sense of belonging (Hoffman et al., 2002; Slaten et al., 2014).

Whether these studies of undergraduates transfer to graduate student populations remains in question, as the literature on graduate students' sense of belonging is comparably limited (O’Meara et al., 2017). The few available studies have found academic success, professional networks, faculty mentoring, and social and academic affirmation as positive contributors to sense of belonging, with students in STEM departments and women who experience microaggressions reporting lower belonging (Curtin et al., 2013; Holloway-Friesen, 2021; O'Meara et al., 2017).

\section{International Student Adjustment Integration, and Belonging}

Most of the existing literature on international students focuses on their academic, social, and cultural adjustment to foreign life. International students who come to the US from different cultures can face significant academic and social challenges (Rivas et al., 2019). Many of these 
students are not familiar with US collegiate academic culture, including pedagogies and grading systems in which there is less supervision and guidance from instructors and more independent learning (Smith and Smith, 1999). Language also poses a problem for students from countries where English is not commonly used, as their developing English language skills may potentially create additional barriers to academic and social adjustment and cause heightened levels of distress and anxiety (Andrade, 2006; Araujo, 2011). In addition to college-related experiences, international students are often confronted with ethnic discrimination and can face culture shock (Constantine et al., 2005; Reynolds and Constantine, 2007). Together these academic, linguistic, and cultural struggles often lead international students to experience feelings of marginalization, loneliness, and isolation (Adelman, 1988; Erichsen and Bolliger, 2011; Sawir et al., 2008).

As efforts to improve the persistence of international students, these studies tend to focus on identifying factors that contribute to international students' adjustment and integration into American universities, with little direct study of belonging. Belonging, a psychological construct, is generally presumed to follow from the involvement-oriented processes of adjustment and integration and is conceptually distinct, however (Hausman, Schofield, and Woods, 2007; Hurtado and Carter, 1997). Furthermore, although departmental characteristics and institutional culture have been studied as determinants of doctoral students' educational experiences (Gardner et al., 2014; Golde, 2005; Lovitts, 2001), there have been few studies that examine graduate students' sense of belonging in specific disciplinary or departmental settings. Curtain et al.'s (2013) quantitative study of international and domestic graduate students is exceptional in this regard, which indicated field differences in sense of belonging (e.g., humanities compared to social sciences). 
This study addresses this gap by exploring students' understanding of their belonging beyond the surface of survey measures. Specifically, we ask: How do male international graduate students in electrical engineering understand and describe their sense of belonging? How do they perceive its development in the context of their graduate program?

\section{Method}

To address the research questions, we conducted a qualitative study of international graduate students at a research university in the United States. An interpretive qualitative approach allows a researcher to illuminate constructions and interpretations of reality at a particular point in time and in a particular context (Merriam, 2002). This method is appropriate for exploring conceptualizations of sense of belonging as it gives students the space to articulate their own understanding of their experiences and allows the researcher to explore students' perspectives of their situations and particular concepts (Creswell, 2009). The institution and all informants discussed in this paper are referred to using pseudonyms to ensure confidentiality.

\section{Date Sources: The Site and Participants}

Oakdale University has a substantial enrollment of international graduate students, making up about one-third of the graduate student population. ${ }^{1}$ Students come from almost one hundred different countries, with approximately half of those students originating from Asia. A large majority of this population is enrolled in engineering and the physical sciences. Oakdale ranks among the top 25 American Research Universities in several higher education ranking systems (Lombardi et al., 2017). Although it is highly ranked, the demographics and enrollment

\footnotetext{
${ }^{1}$ All statistical information about Oakdale University was collected from the official Oakdale website and various reports published by the institution. To ensure confidentiality, the citations and specific statistics that could reveal the institutional identity are omitted.
} 
patterns of international graduate students at Oakdale are reflective of most research institutions in the United States.

We recruited twelve informants for the study using theoretical and judgment sampling (Creswell, 2009). The College of Engineering and the International Student Center provided relevant mailing lists to support recruitment of students for the study. Given that factors such as gender, academic department, and length of stay in the US are known to differentiate experiences and perceptions of international students (Erichsen and Bolliger, 2011; Senyshyn et al., 2000; Tomich et al., 2000), we specifically sampled male, international doctoral students in the electrical engineering department. We do not discount the importance of studying the experiences of women in engineering, as many in the field have argued (Chubin et al., 2005), but limit our sample to men for two reasons. First, we are sensitive to research that illustrates indepth interviews to be "gendered contexts" of similarity or difference, such that the framing of experiences, assumptions of mutual understanding, and expressions of social desirability differ by context and thus can yield data that varies with the interviewer-interviewee gender pairing (Williams \& Heikes, 1993). Second, men interviewing women face greater barriers to establishing rapport and this dynamic may be heightened in male-dominant contexts such as engineering (Andersen, 1993). Since Baek (male, international graduate student in Education at the time of interview) was the sole interviewer, limiting the sampling design to men served to maximize rapport and avoid the bias introduced by a male-female interview context. Within the College of Engineering, we focused on electrical engineering due to its status as the program with the largest enrollment of international graduate students nationally. For country of origin, we strove to reflect the student composition of the department in our sample. Specifically, the sample mainly included the students from the top four countries of origin for graduate students in 
the electrical engineering department: China, India, Turkey, and South Korea. Finally, we restricted the sample to doctoral students with the assumption that the development of a sense of belonging requires some time at an institution and to facilitate sampling informants with varying lengths of residence.

[Table 1 about here]

\section{Data Collection}

The data were collected via semi-structured face-to-face interviews. We conducted two sixty-minute interview sessions with each participant. In the first session, we began the interview by asking the informants to introduce themselves. This opening question was essential to understand each interviewee's background and self-identification at the institution. We introduced sense of belonging as "an individual's perception on whether he or she feels qualified, included, or connected in the institution," which was developed from definitions in previous studies and English dictionaries and included both academic ("qualified") and social ("included" and "connected") meanings. Inquiry focused on students' perceptions of their sense of belonging and its development during their time at Oakdale. We asked them to describe their belonging at the institution and how it has changed during their program. Throughout the interview, instead of asking them to provide a level of their sense of belonging as is done in quantitative studies, we asked participants to share stories of times when they felt a strong or weak sense of belonging to understand how they interpret the construct of sense of belonging. As we were most interested in emic perceptions of belonging, we were careful to ask follow-up questions that minimized interviewer influence on responses.

The second interview facilitated follow-up inquiry, with particular focus on contextual factors such as the broader university and department environment as well as interactions with 
student colleagues, faculty and staff, their residential community, and the campus international community. Participants were asked to order these factors by influence on their sense of belonging each academic year, from least to greatest. We then followed up and asked them to describe how such factors have impacted their belonging over their time in graduate school. With each story and description of growth, students provided us insight into their perspective on the meaning of sense of belonging (see Appendix A for the interview questions).

\section{Data Analysis}

To analyze the collected data, we first reviewed the interview transcriptions and took notes about the overall impressions and meanings of the data. We then initiated a coding process by organizing the transcriptions into different segments of text (Rallis \& Roseman, 2011). We created a codebook with initial codes induced from the raw data and added external codes generated from previous literature and pilot interviews. The codes were refined and merged to generate broader themes, which contributed to developing a conceptual understanding of students' belonging (Creswell, 2009). We used Excel to record interview participants' attributes and the progress of analysis and used Dedoose to organize and analyze the raw data.

Because this study was conducted by two researchers - one who is a Filipino American faculty member and former engineering graduate student and the other who is a former international graduate student in the United States from South Korea, we viewed subjectivity to be inherent in the data collection and analysis process (Peshkin, 1988). We proactively addressed researcher bias through individual and joint reflection throughout the data collection and analysis process (Morrow, 2005). Additionally, we sought review from numerous peer scholars as well as international graduate students throughout the design and analysis process. 


\section{What Does It Mean to Belong? Preeminence of the Academic Domain}

When we asked informants to describe their sense of belonging, all referred to the academic domain immediately, describing factors of academics as most important for feeling accepted, comfortable, and part of the campus. Students discussed academic-related indicators such as GPA, the amount of time they spent with advisors, and research progress when describing what informed their sense of belonging. Even upon initial introductions, ten of the twelve students described their research foci or interests, while only three mentioned hobbies and just two talked about their family background. This conception was supported in the follow-up interviews, as participants once again described moments of academic performance, research work, and academic appraisal by advisors as among the most influential on their sense of belonging at Oakdale.

Hasan, a first-year student from Turkey, conveyed a common sentiment with regard to the centrality of academic belonging: "For me, to feel that I belong to Oakdale is about academics. I mean, how I can belong to Oakdale just with my social life because Oakdale, after all, is an academically high university." He explicitly connects the importance of excelling academically to belonging because of Oakdale's prestigious, academic status. Given the context of graduate education, where socialization goals are likely secondary to academics, the primary linkage to academics is not surprising. Darsh, a first-year student from India, also reflected this attitude as he recalled an occasion when he felt disconnected at the university.

I did not feel a sense of belonging in my first quarter. . . . I had serious doubt about my qualification here at Oakdale, looking at the people around me, seeing how much work I had to put in compared to others. The other people, it didn't seem like they were putting 
as much work as me in class but seemed to be getting better results. So, I felt like I am not smart enough to be at Oakdale.

Darsh experienced a difficult academic transition into graduate school, evaluating his competency in comparative terms to determine his belonging to Oakdale. Nine of the twelve students in the study described belonging in this way, expressing strong convictions about the central role of academic success and measuring their success, critically, in relation to the others.

As doctoral students, the informants also discussed belonging as closely linked to their success in a specific academic realm, the laboratory. Zhen, a first-year student from China, described it this way:

I feel that if the research environment here is very bad, then no matter how good social activities are, I never care about it. The most important, that makes me feel Oakdale is the right place is the research environment. ... Oakdale, more and more, makes me feel that it is exactly right place that can give me very excellent resources in the world. Then, I feel, “okay, it's really nice place, and I belong here."

International graduate students' stronger emphasis on academic belonging may be related to their struggle to obtain a sense of belonging within non-academic contexts. Dongmin, a sixthyear student from South Korea, indicated this sentiment as follows:

If I am good at something here, that makes me feel I belong to Oakdale. Getting good grades, first of all. Maybe that's it. I came here to study so if I am good in the purpose of why I am here, then I feel like, “Okay, I am qualified. I am okay here.” Even if I don't do well in social communication with native speakers, or other international students, I feel like, "Okay, at least I am good at this," the most important thing I came here for. 
Nine students shared stories indicating social and linguistic difficulties, echoing the major findings from the previous literature (Andrade, 2006; Araujo, 2011). Along with the academic emphasis of graduate school, these difficulties may explain why academic belonging was the dominant interpretation of belonging at Oakdale.

\section{Developing Sense of Belonging Through Academic Affirmation}

Each of the students noted that their belonging increased through the course of their studies. This development was primarily grounded in academic confidence gained through various forms of affirmation.

\section{Academic Qualification}

One concrete signal to students regarding their membership in the community at the institution is performance on qualifying exams, which typically occur in the second year in the engineering department. The consequential role of the exams in feeling a sense of belonging was near-universal among these students. Sai, a fifth-year student from India, captured the sense of anxiety with the exam, saying, "When you come into the department, everything is about qualifying exams, that's what people talk about. Everyone, the Ph.D. students, is afraid of it." Hasan made the most explicit connection to belonging, saying, "Once you pass the exam, you feel like you belong to electrical engineering." In other words, failing the exam can diminish one's sense of belonging. Stating that it still hurts to remember, Hajin, who failed the exam in his first attempt, expressed that the experience negatively affected his belonging.

After failing the qualifying exam, I went inside of a cave so I stopped communicating with people, and I lost sense of belonging. I didn't want to do anything. It's kind of embarrassing because people talk about the results, and I didn't want to talk about my results. 
It may not be surprising that the qualifying exam is a significant factor in students' belonging since failing the exam signals eventual departure from the program and the institution.

Beyond the qualifying exams, five students credited successful academic achievement in the classroom to raising their sense of belonging at Oakdale. Peng, a second-year student from China, was not unique in equating belonging to academic achievement.

When I first came here I didn't think I was qualified so I needed to work very hard to get adapted to here. . . . Now my GPA is higher than my colleagues, and I think I work well with my advisor so I think maybe, I don't know, but maybe Oakdale made the right decision. I'm qualified now.

Peng confirmed his belonging through a quantified indicator of his academic qualification for belonging, his GPA. Only after he outperformed his peers on tests did Peng allow himself a sense of successful development of belongingness. While academic performance was important for all students' development of belonging, some students focused on the comparative aspect with peers in describing its importance.

For example, Darsh, who was a very successful student at his undergraduate institution, initially focused on comparisons of academic performance with his peers. He became frustrated when he could not be in the top tier of students at Oakdale, but explained how he developed a sense of belonging at the institution through another domain of academic performance, research. I'm getting used to being in the smart group of people. So I guess my sense of belonging has been improving. ... I have come to accept the fact that I am not as smart, I'm in the middle of the pack. I don't have the same academic status in my class as I did in my undergraduate institute. So it's just accepting the fact and moving on, just living with that. ... Having done research for the last five months, I now feel like I can be a good 
researcher. I might not be good at classes with these people but research is not only about brilliance but also about hard work and discipline, which I think I can be.

\section{The Role of Faculty}

Since doctoral students' research and academic experiences are often influenced by access to resources, as well as advice, feedback, and evaluative critique, faculty and other research staff also appear to be instrumental to the nature and quality of students' belonging. Six students described the attention, advice, and opportunities provided by their advisors as positive influences on their belonging. Zhen, for instance, shared:

My advisor influenced it a lot. He is the one who makes me feel that I am a part of the university. He is the one who took me seriously as a part of his group and also gave me enough freedom, gave me good research problems and told me what things I should pay attention to and what things I can ignore and how to interact with other people. He introduced me to other faculty and gave me an opportunity to give a talk in the department, which is very prestigious because it's rare that a first-year Ph.D. student gives a talk in a forum that is usually given by faculty.

Regarding the importance of an advisor's role, Dongmin provided the most direct association.

My sense of belonging is almost equivalent to qualification. . . I wanted to be recognized by others. And the most significant one who determines that was my professor at that time. My parents have been very satisfied with me. Whatever results I gave them, whatever score, whatever condition I was, they always gave me compliments and made me feel satisfied with my situation. But now I came to the United States, I knew that it should be faculty or professors that I should get recognized instead. 
Lab placements, controlled by faculty advisors, were particularly important in developing an academically-based sense of belonging. Membership in a lab signified faculty confidence and gaining an appointment provided both affirmation and motivation. Darsh remarked:

My advisor's interest aligned a lot with mine and joining her lab, I guess it motivated me, pushed me in the direction for research. Actually, to be honest, at the end of the first quarter, I was in the half mind not do a Ph.D. at all. I thought I would just do a Master's and leave. But then after joining this lab, I felt like, "Oh no, I have a purpose.” ... She is motivating me to keep going with the research.

In general, all of the more senior students in our study described a stronger connection with their advisors than newer students, and the influence of the relationship on their sense of belonging lay heavily in the academic domain.

Not all informants described interactions with faculty and other research staff as positive. Hajin, a third-year student from South Korea, shared this story: "Faculty made me frustrated. Because in my first year, especially the first quarter, they didn't respond to anything, they weren't really responsive and they didn't encourage my research abilities.” Indeed, such narratives were consistent among the informants with regard to their disappointment in the opportunities to obtain affirmation and approval from faculty and staff regarding their qualifications and research abilities and plan, particularly during their early years in the program. The Secondary Role of the Social Domain

While academic relationships, recognition, and success seem to be the most important factors affecting sense of belonging, seven students also described the important role of social friendships. 
Both inside and outside of the class, starting to make a connection of friends slowly made me feel like there is a meaning to why I'm here. . . I I meet with other Oakdale students in an outside setting, and they share all the difficulties that they go through too. In a sense that they say, "I feel the same way too." So that kind of openness encouraged me to feel like, “Okay, so it's not just me."

Sai described how his friendships with other students made him realize that the academic adversity at Oakdale was, in fact, a shared experience. Interestingly, building social relationships consequently helped him enhance not only social belonging but also academic belonging.

Ultimately, social connections like this were often not priorities for participants. While six informants mentioned that interacting with American students would have promoted a sense of belonging as a student in the US, Junsoo's perspective gave voice to the tradeoff with academics perceived by most students in our study. He emphasized that, "The main point of being a graduate student is not learning culture, [but] doing research and showing the performance." Junsoo goes on to explain that engineering graduate students spend eighty percent of their time on research, which is very consuming, leaving little time for socializing.

If you spend the 20 percent of time with other people, it's possible that you might not have enough time to release stress, it might more increase stress. So if you have only one hour, you can just talk with this guy with the common background, and that's more efficient.

This reflection exemplifies the priority students placed on academics - time spent socially had to be efficient - and how investments in the academic and social realm were commensurate with such priorities. 


\section{Belonging in Electrical Engineering}

Students' desire for strong academic belonging was often fostered by their departmental setting of electrical engineering. Among our students, the competitive culture embedded in the engineering department was continually referenced as students measured their belongingness against the yardsticks of academic performance such as grades and qualifying exams. The air of competition led all but the top students to constantly question their academic abilities and thus their belonging at the institution. Competition often interfered with the development of social relationships, as illustrated here by Raphael, a first-year student from France.

You can get to know people from your department but the relationship doesn't really evolve because you always feel that there is some competition and sometimes they ask questions to know how you do in some classes or whatever. And you don't have really this true feeling. Like I am not talking to the person but more like a competitor.

Similar to the influence of the competitive culture, diversity within the department could either contribute to or detract from students' sense of belonging. The electrical engineering department has the largest body of international graduate students at Oakdale. Two informants shared that the majority international student population contributed to their belonging. Junsoo, for example, described belonging at Oakdale as a Korean international student because of the ethnic diversity in his department. He noted:

A sense of belonging to the US is different than a sense of belonging to Oakdale. I feel like Oakdale is not an American school. Particularly in engineering, American is minority. . . . . I think more than 80 percent is Chinese, Indian, and Korean.

In contrast, Hasan pointed out that having a diverse group of students caused nationalitybased divisions within the department: 
Most of the time, in my department, [people from the same nationality] hang out together. . . . For example, you look on Facebook you see photos like, Chinese people went to Santa Cruz; Chinese people went to this place. It is not like some Turkish, some Chinese but all Chinese. I mean, Chinese is an example. It is not just Chinese. Same thing for Indians, same thing for Turkish too. For example, generally I hang out with Turkish friends.

In Hasan's view, the diversity and size of the international population within the department was an obstacle to develop belonging to the groups outside of their comfort zone. This perception was shared by six other students. Even with the desire to build relationships outside of their limited social circle, students were often hesitant to insert themselves in situations that might make them feel vulnerable or uncomfortable.

Additionally, although engineering work increasingly requires communication and collaboration across cultures and disciplines to properly address the political, cultural, and social contexts of its problem spaces (Kalonji, 2005), our participants perceived their work as mostly technical. Interestingly, this perception led them to view the impact of language proficiency differently compared to that seen in previous literature, which identified it as one of the main determinants of international students' belonging. For example, Hasan pointed out:

Not everyone can speak very good English here as I observed. Some people are really bad at speaking English. For engineering, it's fine. It's not required for us to speak very fluent English. We just have to know the symbols, mathematics, etc. This response could be recast as students' naive misunderstanding of the field which in fact requires a high level of writing and communication skills. However, it is still important to 
acknowledge that the international graduate students interviewed in this study did not perceive their English proficiency as essential for success in engineering.

\section{Contextualizing the Understanding of Belonging}

We find that in the context of an electrical engineering doctoral program, the academic domain appears most central to our male international students' interpretation and pursuit of a sense of belonging. All informants indicated that academic-related experiences were the essential contributors, confirming recent research that identifies the academic domain as an important aspect of international graduate students' belonging (Lee et al., 2019; Slaten et al., 2016). Negative experiences such as academic difficulty and poor grades diminished or prevented the development of belonging while academic successes were credited with building it. While previous literature has shown that a sense of belonging facilitates academic success (Hausmann et al., 2007; Ostrove and Long, 2007; Strayhorn, 2012), we find that the relationship is likely bidirectional.

Why do the international graduate students in our study assess their belonging primarily in the academic domain? Certainly, Oakdale's reputation as a top research institution weighs heavily on students' sense of community membership (Curtin et al., 2013). Students' descriptions about their sense of belonging revolve around the self-identification of "I'm a grad student at Oakdale," and this identification appears centered on the notion of academic qualification and success. For doctoral students in particular, their sense of belonging at a research university is closely related to their academic identity (McAlpine et al., 2009). Various formal, semi-formal, and informal activities contribute to the development of the identity; however, students are often expected to manage these activities due to lack of time (McAlpine $e t$ al., 2009). As demonstrated in Junsoo's case, the international graduate students in engineering 
who participated in our study appeared to invest heavily in their academic and research lives at the expense of the social or non-academic components of graduate life.

Students' interpretations of their experiences in this study suggest that the culture of engineering education may define students' non-academic identities and adjustment struggles as irrelevant to belonging. A culture of meritocracy in engineering minimizes institutional responsibility for student success, adjustment, and belonging (Cech, 2013). Many informants pointed out that faculty are inattentive to students in the first years of their programs, but become more involved once students pass the qualifying exam. A logical conclusion among our students is that only the most academically successful students are deserving of their care and attention. In a strongly meritocratic culture, the failure of students is seen as a result of their own lack of dedication, hard work, and talent under a fair and objective system of engineering education. The stakes are raised for academic belonging, and this perception may have been accentuated in a research university context.

The students' strong desire for academic competency and affirmation appears consonant with professional socialization in engineering (Stevens et al., 2008; Weidman and Stein, 2003). Students connected belonging with formative socialization experiences such as positive appraisal and career support from their advisors and external affirmation of their academic abilities through grades, exams, and lab performance. Advisors appear particularly instrumental to this process, as students explicitly referred to their advisors as guides orienting them to their fields and mentors promoting their confidence. Indeed, previous studies have also noted the substantial influence of advisors on students' sense of belonging (Curtin et al., 2016; Holloway-Friesen, 2021; O'Meara et al., 2017). 
Our analyses suggest that male international graduate students in electrical engineering value their relationships with their advisors for two primary reasons: (1) advisors are the primary arbiters of their academic standing and performance; and (2) relationships with advisors are consequential for smooth academic and professional transitions in graduate school. This is consistent with prior research that discussed the effects of mentoring on positive student experiences and outcomes including a sense of belonging (Curtin et al., 2016). Previous literature has also found that students' academic interests, performance, and recognition beliefs play a significant role in fostering "engineering identity" as well as sense of belonging (Rohde et al., 2019; Verdín et al., 2018).

It is important to note that despite the relatively weak focus on the social domain, the informants' understanding of belonging cannot be understood as monolithically academic. Sai locked himself in his room the first few months at Oakdale because he did not have a close group of friends and family members nearby. And prompted by his desire for social connection, Peng navigated his new cultural environment by limiting his social circle only to other Chinese nationals. Such actions clearly connote social desire and mirror research illustrating the connection between social connection and sense of belonging among international students (Sawir et al., 2008). Furthermore, we want to emphasize that social belonging and academic belonging are closely intertwined as one can influence the other and vice versa. For example, it is possible that international students who have more struggles in adjusting to a new environment and have negative experiences with their social belonging may place a greater emphasis on cultivating academic belonging.

Nevertheless, our analyses indicate that building social relationships was largely of secondary importance to our male engineering students, and most did not make concerted efforts 
in that domain. Indeed, students described the development of a strong sense of belonging with little reference to broad social support from peers and faculty theorized as necessary by scholars (Strayhorn, 2012). Furthermore, other factors that might facilitate students' social belonging such as the length of stay in the US or cultural backgrounds were not given significant voice by the students in this study.

Museus (2014) notes that most research on sense of belonging framed by Tinto's model of student departure diminishes or leaves absent psychological dimensions of connectedness, and he proposes that, among other factors, academic motivation is an important interactant with a sense of belonging. The motivations for attending graduate school among our engineering students' appear to be a dominant factor in their conceptualization and pursuit of a sense of belonging. We suspect that the expensive and consequential decision to attend graduate school abroad fuels a sharp and somewhat limited focus on academic success for this population that may be further heightened by the culture of their departments. This motivational aspect may differentiate their experiences from those of domestic graduate students as well as undergraduates as a whole.

\section{Implications and Future Studies}

This study suggests that the meaning and development of students' sense of belonging may differ across student populations with regard to its domain focus, and consequently, supporting such development may require different strategies for specific groups of students. Although we do not intend to generalize our findings to all universities and colleges in the US, the experiences shared by the male international electrical engineering students at Oakdale elicit meaningful implications for how students' motivation to study engineering at the graduate level and the culture of engineering education may influence their belonging. Where the culture 
prioritizes the technical aspect of engineering work over the social and political (Cech, 2013), positive academic experiences and affirmation are imperative to feel qualified, connected, and included in an institution. Understanding this, departments seeking to enhance international graduate students' belonging can be more intentional and broad-reaching in providing opportunities for students to establish positive academic identities. Affirmation mechanisms that are purely impersonal such as grades and exams may be insufficient to provide nuanced support and encouragement for the multiple academic skills and proficiencies exhibited or valued by students, especially in the first two years of doctoral programs. Early advising and mentorship that could have provided more diverse forms of academic affirmation appeared absent for our students. Previous studies have highlighted the positive relationship between mentoring and graduate students' sense of belonging, particularly for marginalized groups (Curtin et al., 2016; Holloway-Friesen, 2021; Le et al., 2016), and called for intentional efforts in mentoring such as training culturally responsive mentors (Sanczyk et al., 2021). In addition, formative, rather than summative, assessments in courses and labs can also provide more timely and personalized feedback and appraisals for students, particularly in the first year of course-taking when initial self-assessments of belonging are being made.

Although this study demonstrates that fostering academic belonging appears paramount for male international graduate students in engineering, we do not discount the importance of fostering social belonging. In fact, addressing students' non-academic identities and experiences of marginalization as relevant to engineering education is necessary to help every student from diverse backgrounds flourish. Conceptually, social belonging is diminished within the culture of engineering education, and taking steps to bring balance to that conception is necessary to fully address belonging for all students. Recent arguments to integrate project-based learning 
(Elshorbagy and Schönwetter, 2002), collaborative learning (Prince, 2004), “hands-on” projects (Joyce et al., 2013), and reflective portfolios (Dunsmore et al., 2011) into the undergraduate engineering curriculum are examples of curricular practices that can provide meaningful engagement with the social and political aspects of engineering learning and work. Successful integration of such pedagogies can also elevate their relevance in the culture. While cultural change can be slow and difficult, documentation of the learning benefits of these studentcentered pedagogies bodes well for their continuing integration and positive effect in loosening the dominant, competitive academic focus of engineering education.

Finally, our work has clear implications for future research. We encourage our work to be followed-up with larger-scale quantitative studies that more broadly test the major hypotheses that emerge from the current study. These include: (1) the academic domain is more relevant to international engineering graduate students' sense of belonging, relative to the social domain; (2) the dominance of academic belonging is invariant across international and domestic graduate students; and (3) the meritocratic and competitive culture of engineering education heightens the academic component of students' belonging. Secondly, our focus on men calls for both parallel and comparative studies of women. Research on women in engineering is particularly important since the relationship between the culture of engineering - a male-dominated environment - and men's conceptions of belonging that is hypothesized in this discussion may not only be unfound among women, it likely obscures an especially challenging environment that defines belonging in a manner that is undesirable for women. Additional research is also needed to address pressing student issues raised by this study. With regard to the dominance of the academic over the social in the culture of engineering, there are implications for the mental wellness of students. Since higher levels of stress, anxiety, and depression are related to perceptions of inclusion among 
engineering students and especially women (Jensen \& Cross, 2021), more research is needed to understand how social belonging is or is not fostered in engineering. Research is also needed to document the relationship between faculty relationships and persistence suggested by the current study but to date has been only fully examined at the undergraduate level (Mayhew et al., 2016). More generally, our qualitative work should be replicated in other institutional and departmental settings to better understand how context interacts with students' conceptions of belonging. 


\section{References}

Adelman, M. B. (1988), “Cross-cultural adjustment: A theoretical perspective on social support”, International Journal of Intercultural Relations, Vol. 12 No. 3, pp.183-204.

Andersen, M. L. (1993), "Studying across difference: Race, class, and gender in qualitative research", Stanfield II, J. H. and Dennis, R. M. (Eds.), Race and Ethnicity in Research Methods, Sage Publications, Inc., Thousand Oaks, CA, pp.39-52.

Andrade, M. (2006), "International students in English-speaking universities: Adjustment factors", Journal of Research in International Education, Vol. 5 No. 2, pp.131-154.

Andrade, M. and Evans, N. (2009), International students: Strengthening a critical resource, Rowman \& Littlefield Education, Lanham, MD.

Araujo, A. D. (2011), “Adjustment issues of international students enrolled in American colleges and universities: A review of the literature", Higher Education Studies, Vol. 1 No. 1, pp.2-8.

Barber, E. G. and Morgan, R. P. (1987), “The Impact of Foreign Graduate Students on Engineering Education in the United States”, Science, Vol. 236 No. 4797, pp.33-37.

Bollen, K. A. and Hoyle, R. H. (1990), "Perceived cohesion: A conceptual and empirical examination", Social Forces, Vol. 69 No. 2, pp.479-504.

Cech, E. A. (2013), "The (mis) framing of social justice: Why ideologies of depoliticization and meritocracy hinder engineers' ability to think about social injustices”, Lucena, J. (Ed.), Engineering Education for Social Justice, Springer, Berlin, Germany, pp.67-84.

Chubin, D. E., May, G. S. and Babco, E. L. (2005), "Diversifying the engineering workforce”, Journal of Engineering Education, Vol. 94 No. 1, pp.73-86. 
Constantine, M. G., Anderson, G. M., Berkel, L. A., Caldwell, L. D. and Utsey, S. O. (2005), "Examining the cultural adjustment experiences of African international college students: A qualitative analysis", Journal of Counseling Psychology, Vol. 52 No. 1, pp.57-66.

Council of Graduate Schools. (2008), Ph.D. completion and attrition: Analysis of baseline demographic data from the Ph.D. completion project. Council of Graduate Schools, Washington, DC.

Creswell, J. W. (2009), Research design: Qualitative, quantitative, and mixed methods approaches, SAGE Publishing, Thousand Oaks, CA.

Curtin, N., Malley, J. and Stewart, A. J. (2016), "Mentoring the next generation of faculty: Supporting academic career aspirations among doctoral students", Research in Higher Education, Vol. 57 No. 6, pp.714-738.

Curtin, N., Stewart, A. J. and Ostrove, J. M. (2013), "Fostering academic self-concept: Advisor support and sense of belonging among international and domestic graduate students", American Educational Research Journal, Vol. 50 No. 1, pp.108-137.

De Wit, H. (2002), Internationalization of higher education in the United States of America and Europe: A historical, comparative, and conceptual analysis, Greenwood Publishing Group, Westport, CT.

Dunsmore, K., Turns, J. and Yellin, J.M. (2011), "Looking toward the real world: Student concpetions of engineering”, Journal of Engineering Education, Vol. 100 No. 2, pp.329348.

Elliott, K. M. (2002), “Key determinants of student satisfaction”, Journal of College Student Retention, Vol. 4 No. 3, pp.271-279. 
Elshorbagy, A. and Schönwetter, D. (2002), “Engineer morphing: bridging the gap between classroom teaching and the engineering profession", International Journal of Engineering Education, Vol. 18 No. 3, pp.295-300.

Erichsen, E. A. and Bolliger, D. U. (2011), “Towards understanding international graduate student isolation in traditional and online environments", Educational Technology Research and Development, Vol. 59 No. 3, pp.309-326.

Faulkner, W. (2000), “Dualisms, hierarchies and gender in engineering”, Social Studies of Science, Vol. 30 No. 5, pp.759-792.

Franzway, S., Sharp, R., Mills, J. E. and Gill, J. (2009), “Engineering ignorance: The problem of gender equity in engineering", Frontiers, Vol. 30 No. 1, pp.89-106.

Freeman, T. M., Anderman, L. H. and Jensen, J. M. (2007), "Sense of belonging in college freshmen at the classroom and campus levels", The Journal of Experimental Education, Vol. 75 No. 3, pp.203-220.

Gardner, S. K., Jansujwicz, J. S., Hutchins, K., Cline, B. and Levesque, V. (2014), "Socialization to interdisciplinarity: Faculty and student perspectives”, Higher Education, Vol. 67 No. 3, pp.255-271.

Golde, C. M. (2005), "The role of the department and discipline in doctoral student attrition: Lessons from four departments", The Journal of Higher Education, Vol. 76 No. 6, pp.669-700.

Goodenow, C. (1993), "Classroom belonging among early adolescent students: Relationships to motivation and achievement", The Journal of Early Adolescence, Vol. 13 No. 1, pp.2143. 
Gu, Q., Schweisfurth, M. and Day, C. (2010), "Learning and growing in a 'foreign'context: Intercultural experiences of international students", Compare, Vol. 40 No. 1, pp.7-23.

Han, X., Stocking, G., Gebbie, M. A. and Appelbaum, R. P. (2015), "Will they stay or will they go? International graduate students and their decisions to stay or leave the US upon graduation”, PloS one, Vol. 10 No. 3, pp.1-18.

Hausmann, L. R., Schofield, J. W. and Woods, R. L. (2007), "Sense of belonging as a predictor of intentions to persist among African American and White first-year college students", Research in Higher Education, Vol. 48 No. 7, pp.803-839.

Hoffman, M., Richmond, J., Morrow, J. and Salomone, K. (2002), “Investigating sense of belonging in first year college students", Journal of College Student Retention, Vol. 4 No. 3, pp.227-256.

Holloway-Friesen, H. (2021), “The role of mentoring on Hispanic graduate students' sense of belonging and academic self-efficacy", Journal of Hispanic Higher Education, Vol. 20 No. 1, pp.46-58.

Hurtado, S. and Carter, D. F. (1997), "Effects of college transition and perceptions of the campus racial climate on Latino college students' sense of belonging”, Sociology of Education, Vol. 70 No. 4, pp.324-345.

Hurtado, S. and Ponjuan, L. (2005), "Latino educational outcomes and the campus climate", Journal of Hispanic Higher Education, Vol. 4 No. 3, pp.235-251.

Institute of International Education. (2020), “IIE Open Doors Fast Facts 2020”, retrieved from https://opendoorsdata.org/fast_facts/fast-facts-2020

Jensen, K. J. and Cross, K. J. (2021), “Engineering stress culture: Relationships among mental health, engineering identity, and sense of inclusion", Journal of Engineering Education. 
Johnson, D. R. (2012), “Campus racial climate perceptions and overall sense of belonging among racially diverse women in STEM majors", Journal of College Student Development, Vol. 53 No. 2, pp.336-346.

Johnson, D. R., Soldner, M., Leonard, J. B., Alvarez, P., Inkelas, K. K., Rowan-Kenyon, H. T., and Longerbeam, S. D. (2007), "Examining sense of belonging among first-year undergraduates from different racial/ethnic groups", Journal of College Student Development, Vol. 48 No. 5, pp.525-542.

Joyce, T., Evans, I., Pallan, W. and Hopkins, C. (2013), “A hands-on project-based Mechanical Engineering design module focusing on fustainability", Engineering Education, Vol. 8 No. 1, pp.65-80.

Kalonji, G. (2005), "Capturing the imagination: High-priority reforms for engineering educators", National Academy of Engineering (Ed.), Educating the Engineer of 2020: Adapting Engineering Education to the New Century, National Academies Press, Washington, DC, pp.146-150.

Kuh, G., D., Kinzie, J., Buckley, J., A., Bridges, B., K. and Hayek, J., C. (2006), What matters to student success: A review of the literature, National Postsecondary Education Cooperative, Washington, DC.

Laufer, M. and Gorup, M. (2019), “The invisible others: stories of international doctoral student dropout", Higher Education, Vol. 78 No. 1, pp.165-181.

Le, A. T., LaCost, B. Y. and Wismer, M. (2016), “International female graduate students' experience at a midwestern university: Sense of belonging and identity development", Journal of International Students, Vol. 6 No. 1, pp.128-152. 
Lee, E., Bekki, J. M., Carberry, A. R. and Kellam, N. N. (2019), “Understanding international engineering doctoral students' sense of belonging through their interpersonal interactions in the academic community", in 2019 CoNECD-The Collaborative Network for Engineering and Computing Diversity, Crystal City, VA.

Lombardi, J. V., Phillips, E. D., Abbey, C. W. and Craig, D. D. (2017), The Top American Research Universities: 2017 Annual Report, The Center for Measuring University Performance, Amherst, MA.

Lovitts, B. E. (2001), Leaving the ivory tower: The causes and consequences of departure from doctoral study, Rowman \& Littlefield, Lanham, MD.

Mayhew, M. J., Rockenbach, A. N., Bowman, N. A., Seifert, T. A. and Wolniak, G. C. (2016), How college affects students: 21 st century evidence that higher education works, John Wiley \& Sons, Hoboken, NJ.

McAlpine, L., Jazvac-Martek, M. and Hopwood, N. (2009), "Doctoral student experience in education: Activities and difficulties influencing identity development", International Journal for Researcher Development, Vol. 1 No. 1, pp.97-109.

Meeuwisse, M., Severiens, S. E. and Born, M. P. (2010), "Learning environment, interaction, sense of belonging and study success in ethnically diverse student groups", Research in Higher Education, Vol. 51 No. 6, pp.528-545.

Merriam, S. B. (2002), Qualitative research in practice: Examples for discussion and analysis, Jossey-Bass Inc Pub, San Francisco, CA.

Mervis, J. (2017), “Drop in foreign applicants worries engineering schools”, Science, Vol. 355 No. 6326, pp.676-677. 
Morrow, S. L. (2005), “Quality and trustworthiness in qualitative research in counseling psychology", Journal of Counseling Psychology, Vol. 52 No. 2, pp.250-260.

Museus, S. D. (2014), “The culturally engaging campus environments (CECE) model: A new theory of success among racially diverse college student populations”, Paulsen, M. B. (Ed.), Higher Education: Handbook of Theory and Research, Springer, New York, NY, pp.189-227.

Museus, S. D., Yi, V. and Saelua, N. (2017), “The impact of culturally engaging campus environments on sense of belonging", The Review of Higher Education, Vol. 40 No. 2, pp.187-215.

National Foundation for American Policy. (2017), “The importance of international students to American science and engineering", retrieved from https://nfap.com/wpcontent/uploads/2017/10/The-Importance-of-International-Students.NFAP-PolicyBrief.October-20171.pdf

O'Meara, B. K., Griffin, K. A., Kuvaeva, A., Nyunt, G. and Robinson, T. (2017), "Sense of belonging and its contributing factors in graduate education", International Journal of Doctoral Studies, Vol. 12 No. 12, pp.251-279.

Ostrove, J. M. and Long, S. M. (2007), “Social class and belonging: Implications for college adjustment", The Review of Higher Education, Vol. 30 No. 4, pp.363-389.

Peshkin, A. (1988), “In Search of Subjectivity_One's Own”, Educational Researcher, Vol. 17, pp.17-21.

Prince, M. (2004), “Does active learning work? A review of the research”, Journal of Engineering Education, Vol. 93 No. 4, pp.223-231. 
Rallis, S. F. and Rossman, G. B. (2011), Learning in the field: An introduction to qualitative research, Sage Publications, Inc., Thousand Oaks, CA.

Reynolds, A. L. and Constantine, M. G. (2007), “Cultural adjustment difficulties and career development of international college students", Journal of Career Assessment, Vol. 15 No. 3, pp.338-350.

Rivas, J., Hale, K. and Burke, M. G. (2019), "Seeking a sense of belonging: Social and cultural integration of international students with American college students", Journal of International Students, Vol. 9 No. 2, pp.682-704.

Rohde, J., Musselman, L., Benedict, B., Verdín, D., Godwin, A., Kirn, A., Benson, L. and Potvin, G. (2019), “Design experiences, engineering identity, and belongingness in early career electrical and computer engineering students", IEEE Transactions on Education, Vol. 62 No. 3, pp.165-172.

Sanczyk, A., Merriweather, L. R., Howell, C. D. and Douglas, N. C. (2021), "STEM doctoral mentoring: a call for a conscious, culturally responsive journey", International Journal of Mentoring and Coaching in Education, pp.1-14.

Sawir, E., Marginson, S., Deumert, A., Nyland, C. and Ramia, G. (2008), “Loneliness and international students: An Australian study", Journal of Studies in International Education, Vol. 12 No. 2, pp.148-180.

Senyshyn, R. M., Warford, M. K. and Zhan, J. (2000), "Issues of adjustment to higher education: International students' perspectives", International Education, Vol. 30 No. 1, pp.17-35.

Slaten, C.D., Elison, Z.M., Lee, J.Y., Yough, M. and Scalise, D. (2016), "Belonging on campus: A qualitative inquiry of Asian international students", The Counseling Psychologist, Vol. 44, pp.383-410. 
Slaten, C. D., Yough, M. S., Shemwell, D. A., Scalise, D. A., Elison, Z. M. and Hughes, H. A. (2014), "Eat, Sleep, Breathe, Study: Understanding What It Means to Belong at a University from the Student Perspective”, Excellence in Higher Education, Vol. 5 No. 1, pp.1-5.

Smith, P. J. and Smith, S. N. (1999), "Differences between Chinese and Australian students: some implications for distance educators", Distance Education, Vol. 20 No. 1, pp.64-80.

Stevens, R., O'connor, K., Garrison, L., Jocuns, A. and Amos, D. M. (2008), “Becoming an engineer: Toward a three dimensional view of engineering learning”, Journal of Engineering Education, Vol. 97 No. 3, pp.355-368.

Strayhorn, T. L. (2012), College students' sense of belonging: A key to educational success for all students, Routledge, New York, NY.

Stuen, E. T., Mobarak, A. M. and Maskus, K. E. (2012), “Skilled immigration and innovation: evidence from enrolment fluctuations in US doctoral programmes", The Economic Journal, Vol. 122 No. 565, pp.1143-1176.

Tinto, V. (1975), "Dropout from higher education: A theoretical synthesis of recent research", Review of Educational Research, Vol. 45 No. 1, pp.89-125.

Tinto, V. (1987), Leaving college: Rethinking the causes and cures of student attrition, The University of Chicago, Chicago, IL.

Tinto, V. (2017), “Through the eyes of students”, Journal of College Student Retention, Vol. 19 No. 3, pp.254-269.

Tomich, P., McWhirter, J. J. and King, W. E. (2000), “International student adaptation: Critical variables", International Education, Vol. 29 No. 2, pp.37-46. 
Tovar, E. and Simon, M. A. (2010), "Factorial structure and invariance analysis of the sense of belonging scales", Measurement and Evaluation in Counseling and Development, Vol. 43 No. 3, pp.199-217.

Verdín, D., Godwin, A. and Ross, M. (2018), “STEM roles: How students’ ontological perspectives facilitate STEM identities", Journal of Pre-College Engineering Education Research, Vol. 8 No. 2, Article 4.

Walton, G. M. and Brady, S. T. (2017), “The many questions of belonging”, Elliot, A. J., Dweck, C. S. and Yeager, D. S. (Eds.), Handbook of competence and motivation: Theory and application, The Guilford Press, New York, NY, pp.272-293.

Walton, G. M. and Cohen, G. L. (2007), “A question of belonging: Race, social fit, and achievement", Journal of Personality and Social Psychology, Vol 92 No. 1, pp.82-96.

Weidman, J. C. and Stein, E. L. (2003), "Socialization of doctoral students to academic norms", Research in Higher Education, Vol. 44 No. 6, pp.641-656.

Williams, C. L. and Heikes, E. J. (1993), “The importance of researcher's gender in the in-depth interview: Evidence from two case studies of male nurses", Gender \& Society, Vol. 7 No. 2, pp.280-291. 
Table 1

Informant Characteristics

\begin{tabular}{lll}
\hline Pseudonym & Years in the Ph.D. program & Country of Origin \\
\hline Darsh & 1st year & India \\
Yusuf & 1st year & Turkey \\
Hasan & 1st year & Turkey \\
Zhen & 1st year & China \\
Raphael & 1st year & France \\
Mustafa & 2nd year & Turkey \\
Peng & 2nd year & China \\
Liang & 2nd year & China \\
Hajin & 3rd year & South Korea \\
Sai & 5th year & India \\
Dongmin & 6th year & South Korea \\
Junsoo & 6th year & South Korea \\
\hline
\end{tabular}




\section{Appendix A}

\section{Interview Protocol}

\section{First Interview Session}

1. Please briefly introduce yourself / please tell me about yourself

2. Please describe what type of "student" you are

3. Please describe your transition to Oakdale as a graduate student

4. Please describe your sense of belonging to Oakdale in your first year

a. Tell me a story of a particular time when you felt a strong sense of belonging at Oakdale in your first year.

b. Tell me a story of a particular time when you felt a less sense of belonging at Oakdale in your first year.

5. Please describe your sense of belonging to Oakdale in your second year (and following years)

a. Tell me a story of a particular time when you felt a strong sense of belonging at Oakdale in your second year.

b. Tell me a story of a particular time when you felt a less sense of belonging at Oakdale in your second year.

c. How was different/same from the previous year?

6. In sum, how would you describe your sense of belong over the time?

7. What can the university do to improve your sense of belonging?

8. Is there anything you would do differently / you would recommend for the incoming Ph.D. students (to improve sense of belonging)? 


\section{Second Interview Session}

- Prepare flash cards with the following words written:

University, Department/School, Cohort, Faculty and Staff (including Advisor), Residential

Community, International Community

- Put these factors in order that had influenced your sense of belonging from least to greatest

○ Reflecting your first year

- Reflecting your second year (and following years)

- Please tell me why you put each component in that order 